\title{
Siguiendo la coyuntura 1990-1992: "y la violencia y el desorden crearon a Fujimori..."
}

Recibido: 06/09/2018

Aprobado: 02/1 1/2018

\author{
SANTIAGo PEDRAGLIO \\ Pontificia Universidad Católica del Perú \\ spedraglio@pucp.pe
}

\section{RESUMEN}

Este artículo se centra en las elecciones de 1990, en el contexto de una aguda crisis económica y política que permitió la victoria, sobre Mario Vargas Llosa, de un desconocido: Alberto Fujimori. Finalizado el periodo electoral, la situación de excepción — configurada gradualmente durante la década de 1980 por el accionar de Sendero Luminoso, la constitución de comandos político-militares y la gran crisis política y económica - ingresó en una nueva coyuntura. Fujimori cambió su discurso político e inició la organización de una amplia coalición conservadora en torno a un proyecto neoliberal

Palabras clave: Perú, Alberto Fujimori, Sendero Luminoso, situación de excepción, coyuntura.

\section{Following the moment 1990-1992: "and violence and disorder created Fujimori..."}

\begin{abstract}
This article focuses on the 1990 elections, in the context of an acute economical and political crisis that allowed an unknown, Alberto Fujimori, the victory over Mario Vargas Llosa. After this electoral period, the state of exception - configured gradually during the decade of 1980 by the actions of the Shining Path, the constitution of paramilitary commandos and the generalized economic and political crisis - entered into a new context. Fujimori changed his political discourse and initiated the organization of a broad conservative coalition around a neoliberal project.
\end{abstract}

Keywords: Peru, Alberto Fujimori, Shining Path, state of exception.

1 Adaptación de los capítulos I y II de la tesis Cómo se llegó a la dictadura consentida. El Gobierno de Alberto Fujimori: 1990-1992, presentada en la Universidad Nacional Mayor de San Marcos para optar por el grado académico de magíster en Sociología, con mención en Sociología Política, sustentada el 10 de julio del 2014. 


\section{Introducción}

- Cómo y por qué se gestan y legitiman, en el Perú, los regímenes autoritarios y dictatoriales? Nuestra sociedad está marcada por este tipo de gobiernos, con un fuerte componente caudillista. Muchas generaciones han crecido bajo regímenes dictatoriales o autoritarios, militares o civiles, liderados por caudillos, lo que gravita en la formación de la cultura política y en el ejercicio de la ciudadanía.

La observación de los dos primeros años de Gobierno de Alberto Fujimori (1990-1992), desde su elección en julio de 1990 hasta la captura de Abimael Guzmán en setiembre de 1992, pasando por el decisivo autogolpe del 5 de abril de ese mismo año, permite explorar el tema y abordar el encumbramiento tanto de una dictadura como de un caudillo.

Este artículo se centra en algunos de los principales factores que, entre 1980 y 1990, crearon la coyuntura de excepción que el país vivió de 1990 a 1992, en particular en la fase inicial de la victoria electoral de Alberto Fujimori, las condiciones en las que se produjo y su instalación en el poder el 28 de julio de 1990.

\section{Antecedentes de la excepcionalidad}

Entre 1990 y 1992 el Perú vivió una situación de excepcionalidad en los ámbitos político, económico y militar, que tuvo sus orígenes durante la década anterior, más precisamente con el inicio de la acción armada de Sendero Luminoso en abril de 1980, y en la consiguiente respuesta política y militar del Estado. Pocos años después, a partir de 1987-1988, esta situación excepcional se agudizó con el agravamiento incesante de la crisis económica y la hiperinflación.

Sendero Luminoso consiguió entre 1980 y fines de diciembre 1982 hacerse de una cierta base social rural y entablar una dura confrontación con la Policía Nacional del Perú (PNP). Hubo bajas de ambos lados y la Policía capturó a importantes cuadros de Sendero en el territorio de su llamado Comité Principal: Ayacucho, Apurímac y Huancavelica, en especial en las zonas rurales. Sin embargo, la falta de acción nacional y concertada del Estado limitó la eficiencia de la Policía. Además, el cruento asalto a la cárcel de Huamanga (Ayacucho), por un comando senderista, en marzo de 1982, que permitió la fuga de más de 
trescientos presos (de los cuales aproximadamente setenta eran senderistas), fue un duro político y mediático contra el Gobierno y la Policía.

Desde el Estado, los brotes de excepcionalidad escalaron en enero de 1983 con la intervención de los militares en Ayacucho. La decisión del Gobierno de Fernando Belaunde, al aprobar la participación directa de los militares, no tuvo otro propósito que intentar enfrentar y derrotar — se creyó que rápidamente - al entonces casi desconocido pero creciente Sendero Luminoso. En las zonas de emergencia, la Policía pasó a estar subordinada a los comandos político-militares. Belaunde no previó las consecuencias: aumento exponencial de muertos y maltrato a la población, evidente desconocimiento del enemigo, exigencias mayores de una conducción política del conflicto militar interno, y control, por los militares, de grandes porciones del poder político, sobre todo en los territorios sometidos al conflicto armado.

En el plano económico, la excepcionalidad tuvo su desembalse drástico e inicial en 1988, cuando colapsó el programa económico, calificado como heterodoxo o populista, aplicado por el primer Gobierno de Alan García (19851990). Esto propició el aumento exponencial de la inflación, la reconfiguración de la sociedad y el quiebre de la estructura laboral y productiva del país.

En el aspecto político se alcanzó un grado de excepcionalidad extrema entre la campaña electoral presidencial de 1990 y la detención de Guzmán en setiembre de 1992, pasando por el autogolpe de Estado del 5 de abril de ese mismo año. La situación de excepcionalidad extrema no concluyó con el autogolpe, sino en 1995, con la segunda elección de Fujimori —que legitimó el golpe de tres años antes - y, sobre todo, con la nueva Constitución aprobada en 1993.

La Comisión de la Verdad y Reconciliación (CVR) se refiere al periodo marzo de 1989-setiembre de 1992 (fecha de detención de Abimael Guzmán), como de "crisis extrema, ofensiva subversiva y contraofensiva estatal" (CVR, 2004, p. 72).

Con el incremento de la violencia interna - el esfuerzo de Sendero Luminoso por conseguir el "equilibrio estratégico" y su creciente presencia propagandística y armada en los centros urbanos-, la crisis económica y la incapacidad del Gobierno para controlarla, el Perú ingresó en un momento en que el poder político se expresa de manera directa, con débiles canales de representación y una muy baja legitimidad social. Las formas de intermediación y representación propias de la democracia liberal se hacen cada vez más tenues y frágiles, y se abre el espacio para que las fuerzas crudas se expresen de manera incontrolable. 
No obstante, es posible rastrear la construcción de la excepcionalidad desde la década anterior. El artículo 211, inciso 20 de la Constitución de 1979, otorgó al presidente la capacidad de "dictar medidas extraordinarias en materia económica y financiera, cuando así lo requiere el interés nacional y con cargo de dar cuenta al Congreso". Los alcances de este artículo se establecieron durante la década de 1980, en un proceso que Eguiguren (1986, p. 215) llama “mutación constitucional". Fernando Belaunde (1980-1985) dictó 667 medidas extraordinarias; y Alan García (1985-1990), 1033. Igualmente, merced al artículo 231 de la misma Carta, el Ejecutivo adquirió la facultad de decretar un estado de emergencia prorrogable cada sesenta días, incluso sin la aprobación del Congreso, así como de decretar estado de sitio, cuya prórroga sí requería la aprobación del Congreso (Kenney, 1997, p. 79).

A propósito de las situaciones de excepción y de la "dictadura comisarial", Carl Schmitt (2007, p. 49) sostiene que "quien domine al estado de excepción, domina con ello al Estado, porque decide cuándo debe existir este Estado y qué es lo que la situación de las cosas exige. Así, todo derecho termina por ser referido a la situación de las cosas".

En el Perú, la situación se definía crecientemente a favor del más fuerte, del que tenía más poder, entendido el término a partir de la larga tradición del pensamiento político representada por Schmitt, Max Weber y Carlos Marx -y antes por Nicolás Machiavelo y Thomas Hobbes -.${ }^{2}$ La comprensión de Schmitt (2007, p. 50) sobre la resolución de estos momentos ayuda a entender la gravedad de la crisis: "En los asuntos públicos, en el derecho de guerra, de misión diplomática, municipal y estatal, no decide la aequitas, sino la vis dominationes, es decir, alianzas, soldados y dinero".

La opinión de Schmitt, bastante cercana en este punto al clásico concepto marxista de situación revolucionaria, ${ }^{3}$ no tiene por qué desvincularse de la importancia de la legitimidad que tuvieron los actos de fuerza utilizados en esa situación excepcional que vivió el país. No estaban en juego solamente la violencia física ni quién tenía o podía utilizarla más y mejor, sino quién tenía el mayor

2 Visión a la que se contrapone Hannah Arendt (1997), quien subraya la necesidad de distinguir entre poder, fuerza y potencia, y considera que el poder es esencialmente consenso.

3 “¿Cuáles son, en términos generales, los signos distintivos de una situación revolucionaria? [...] 1) La imposibilidad para las clases dominantes de mantener su dominio en forma inmutable. [...] 2) Una agravación, superior a la habitual, de la miseria y las penalidades de las clases oprimidas. 3) Una intensificación considerable, por las razones antes indicadas, de la actividad de las masas, que en tiempos 'pacíficos' se dejan expoliar tranquilamente, pero que en épocas turbulentas son empujadas, tanto por la situación de crisis en conjunto como por las 'alturas' mismas, a una acción histórica independiente. [...] El conjunto de estos cambios objetivos es precisamente lo que se llama situación revolucionaria" (Lenin, 1915). 
control del conjunto de los instrumentos de poder, en los que la violencia física es un componente fundamental. La década de 1980 condensó no solo la lucha del Estado contra los grupos subversivos, sino también la confrontación entre el Gobierno aprista, representante de un desarrollo capitalista nacional, y los grandes empresarios, crecientemente inclinados hacia una propuesta neoliberal.

Las Fuerzas Armadas, debido a su importancia decisiva para controlar el territorio, adquirieron creciente autonomía y se convirtieron, con Sendero Luminoso, en actores políticos decisivos. Paralelamente, la opinión pública tuvo un papel importante pero pasivo; no definía el rumbo de lo que Schmitt denomina "la situación de las cosas". Solo adquirió protagonismo cuando se manifestó de manera organizada no solo a través de las movilizaciones empresariales en alianza con los grandes medios de comunicación frente a la estatización de la banca, sino sobre todo vía las rondas campesinas o comités de autodefensa cuando trataban de controlar el territorio en su lucha contra Sendero Luminoso. Los sindicatos, los gremios populares y profesionales, los partidos, así como los organismos representativos del Estado, caso el Congreso de la República, tenían un papel crecientemente marginal. La crisis de excepcionalidad hizo que se redujeran los actores con capacidad de decisión; y que su lucha por influir en "la situación de las cosas" se instalara por fuera de la democracia representativa y sus organismos, e incluso de la Constitución.

La coyuntura de tensión extrema abrió el espacio para que los gobernantes, con el mayoritario apoyo de los peruanos, asumieran conductas extraordinarias y dictatoriales que violaron o dejaron en suspenso la Constitución, y que pusieron por delante los intereses primarios del Estado. En el momento decisivo de la coyuntura de excepcionalidad, las fuerzas reformistas de izquierda o de centro - llámense Izquierda Unida o APRA—, derrotadas por crisis internas, por carecer de una propuesta democrática realista o por una desastrosa gestión de Gobierno, tuvieron escasas posibilidades de enrumbar hacia un manejo democrático de la crisis.

\section{1. ¿Cómo interpretaron la excepcionalidad los actores politicos y sociales?}

La crisis económica, la inflación galopante, ${ }^{4}$ la agresiva acción armada de Sendero Luminoso y la importante implantación de la Izquierda Unida en de-

4 "El Gobierno de García Pérez dejó el país sumido en una profunda crisis económica y social, con una inflación anual superior a 2775\% en 1989 y, en lo relativo a la violencia, con 65 provincias y un distrito en estado de emergencia” (Reátegui, 2009, p. 175). 
terminadas organizaciones sociales y zonas populares del país hicieron pensar no solo a Sendero y a algunos sectores de la izquierda legal, sino también a militares conservadores - admiradores de Pinochet, que en ese mismo periodo elaboraron el Plan Verde - que era posible que la polarización política izquierda-derecha se convirtiera en la predominante, en revolucionaria, que podía ser utilizada a su favor por las organizaciones subversivas, o por la Izquierda Unida a través de elecciones o formas mixtas de lucha de masas y electorales para obtener el poder.

No obstante, esta aparente cercanía a una situación revolucionaria estuvo lejos de madurar, ${ }^{5}$ como aspiraban Sendero Luminoso y, desde otra perspectiva política y programática, ciertos sectores de la Izquierda Unida. En primer lugar, porque los actores que hubieran podido transformarla en una coyuntura de cambio democrático radical — sobre todo los de la Izquierda Unida — estaban anticipadamente derrotados, además de demostrar en los hechos no tener la voluntad efectiva de ganar el Gobierno con un programa de reformas democráticas y radicales; ${ }^{6}$ en segundo lugar, porque las fuerzas políticas más activas y beligerantes, Sendero Luminoso y, sobre todo, el MRTA, no dejaron de ser nacionalmente marginales (a pesar de su beligerancia, en especial Sendero); $\mathrm{y}$, en tercer término, porque las vastas y disímiles fuerzas sociales, políticas y culturales "prosistema" - esto es, favorables al orden estatal vigente, a la preservación de los poderes comunales rurales o locales, a la democracia representativa o a la defensa de las tradiciones - se vieron especialmente activadas por la acción subversiva, y pasaron a ser un contingente más poderoso que el representado y expresado por los llamados partidos tradicionales.

El cálculo de Sendero Luminoso - y de quienes tenían una evaluación semejante - de que era posible transitar desde esa crisis a una situación revolucionaria fracasó rotundamente. Lejos de establecerse como preocupación medular de los peruanos la revolución o el cambio reformista radical, los factores centrales de la coyuntura — violencia e hiperinflación- hicieron que prevaleciera, como llamado esencial y primero a los gobernantes, la urgencia de establecer el orden como garantía para la vida.

5 Durante los años finales del primer Gobierno de García y los primeros de Fujimori, el embajador de un país vecino me narró con detalle ciertas coordinaciones de intervención, preparatorias y preventivas, de países vecinos y de los Estados Unidos, ante un eventual escenario de colapso del Estado peruano, quizá incapaz de contener la arremetida de Sendero Luminoso.

6 La Izquierda Unida se divide en su congreso nacional de 1988 debido a una combinación de supuestas razones estratégicas — para decirlo en sencillo: "reforma o revolución"— y por los cupos electorales de cara a las elecciones de 1990. 
Los partidos políticos de izquierda, centro o derecha fueron incapaces de controlar el territorio y colaborar con la instauración de un sólido orden democrático. Se demostraron incapaces de controlar el aumento de la violencia política. La violencia se les escapó de las manos y, consiguientemente, porciones cada vez mayores del territorio y del propio Estado. La política, afirma Max Weber (2004), es en última instancia la administración de la violencia. El hecho de que los partidos políticos y, sobre todo, los propios gobiernos democráticos dejaran gradualmente de controlar el uso de la violencia estatal fue la manifestación más dramática de su derrota y, finalmente, de su creciente marginalidad. Sobre todo, rehuyeron su responsabilidad central de darle una conducción política democrática a las Fuerzas Armadas. Con eso, la crisis de la democracia y de los partidos políticos ya estaba instalada. El periodo de 1990 a 1992 sería, simplemente, su desembalse.

\section{El triunfo de Fujimori, la derrota de las opciones "populares" y el cambio de humor de la población}

La instalación del orden como eje de la agenda política - $-\mathrm{y}$ condición para imponer el proyecto neoliberal - expresa la situación de excepcionalidad que se vivió en el Perú durante esos años. Esto consolidó a un político aventurero, hábil y autoritario como Alberto Fujimori y a los promotores del modelo económico que se venía imponiendo en casi todos los países de la región.

Ante la crisis económica y el avance de Sendero, la incertidumbre ganó espacio entre la población. El dato a resaltar, no obstante, es que el malestar y la ansiedad, producto del incremento del desempleo y del empleo precario, como también de la quiebra de empresarios, no pudieron ser canalizados por las fuerzas políticas populares.

La segunda vuelta electoral, que permitió el triunfo de Alberto Fujimori (Cambio 90) sobre Mario Vargas Llosa (FREDEMO), ${ }^{7}$ fue el canto del cisne de las fuerzas reformistas que, derrotadas o divididas, aspiraban confusamente a mantener la democracia precaria, administrar la crisis económica y derrotar a Sendero en el marco del inestable y sumamente recortado pero aún vigente Estado de derecho.

7 Frente Democrático. 
El surgimiento de un "independiente" como Alberto Fujimori expresó la crisis de representación de los partidos tradicionales que habían prevalecido durante la década de 1980, después de que se reinstalara la democracia con el Gobierno de Fernando Belaunde. Pero el surgimiento de los independientes ${ }^{8}$ era también la expresión de la derrota de los partidos, manifiesta en la desaparición o disminución radical de su representatividad, pero también de su credibilidad. Los partidos fueron "licuados" por la crisis en un breve lapso, el lustro 1985-1990. La derrota no se hizo evidente con los resultados electorales de 1990, pero fue concluyente la forma como un aventurero, Alberto Fujimori, adquirió la capacidad necesaria para convocar a los poderes fácticos, crear nuevas lealtades y, sobre todo, terminar de destruir el sistema político y las bases productivas existentes.

El primer gran aviso de su éxito futuro surgió cuando, contra todo supuesto, las drásticas medidas aprobadas y aplicadas por el primer gabinete de Alberto Fujimori en agosto de 1990 recibieron el apoyo mayoritario de la ciudadanía. Era la manifestación de cuán escasamente sintonizados con la población estaban los partidos políticos, incluyendo a la Izquierda Unida.

\subsection{El canto del cisne del reformismo iniciado con Velasco y el triunfo del aventurero}

La coyuntura electoral que se vivió en 1990, en particular las semanas entre la primera y la segunda vuelta, permite afirmar que el triunfo del entonces desconocido Alberto Fujimori sobre Mario Vargas Llosa constituyó la última gran resistencia de las fuerzas políticas y sociales que pretendían mantener reglas económicas y políticas básicas instauradas durante el Gobierno militar de Juan Velasco Alvarado y en parte de la década de 1980, en especial durante el Gobierno de Alan García. Canto final de fuerzas que pretendían impulsar cambios radical-revolucionarios desde el interior del sistema político.

En la década de 1960, y en particular durante el Gobierno militar del general Velasco (1968-1975), se impulsó un reordenamiento de la economía y de la política que terminó por quebrarse con el autogolpe de 1992. El régimen militar

$8 \quad$ Para Nicolás Lynch (1999, pp. 233, 261): "Los independientes surgen como actores políticos relevantes el año 1989 con la elección de Ricardo Belmont a la alcaldía de Lima. 1989 es un año crítico para la democracia peruana porque en él los problemas irresueltos en la década que terminaba se hacen presentes en toda su magnitud y los principales actores partidarios muestran grave incapacidad para resolverlos. [...] Este liderazgo plebiscitario de los independientes se basa en una legitimidad por resultados que subordina a cualquier legitimidad legal que el régimen autoritario quiera darse". 
instauró un modelo político y económico basado en eliminar a la oligarquía, limitar la propiedad privada, estimular desde el Estado la organización popular, generar nuevos símbolos de identidad nacional — como Túpac Amaru y el reconocimiento del quechua como idioma oficial — y refrendar la preeminencia de la política y de la voluntad política sobre la economía, vía un capitalismo de Estado preñado de tensiones con el gran capital, en especial el norteamericano.

Ni el segundo Gobierno de Fernando Belaunde (1980-1985) ni el de Alan García (1985-1990) rompieron las reglas de juego básicas instauradas por el velasquismo. Es verdad que durante el Gobierno militar del general Francisco Morales Bermúdez (1975-1980), y en el segundo periodo de Belaunde, hubo intentos - más decididos en el segundo que en el primero- de liberalizar la economía y romper el pensamiento político hegemónico impuesto por el reformismo militar, consistente básicamente en defender la idea de un proyecto nacional inclusivo asentado en una activa presencia del Estado. Sin embargo, a pesar de los cambios parciales en la economía y de la restauración de la democracia, las claves de la política, de la economía y del humor político cultural se mantuvieron inalteradas.

El desmoronamiento del llamado Estado populista se inició en 1987, con el fracaso del programa heterodoxo del Gobierno de Alan García y, contradictoriamente, de la mano de su decisión de estatizar la banca. Sin embargo, durante los dos primeros años del Gobierno de Fujimori es cuando se termina de desmontar el régimen estatal y social construido desde fines de la década de 1960 por el Gobierno de Velasco.

El momento decisivo de manifestación de esta postrera resistencia tuvo lugar cuando se enfrentaron, en la segunda vuelta electoral, el bloque reformista conformado por el APRA, la izquierda, las dirigencias de frentes regionales y barriales, los sindicatos y el candidato Fujimori contra el bloque de derecha que respaldaba la candidatura de Mario Vargas Llosa, del FREDEMO: Acción Popular, Partido Popular Cristiano, Movimiento Libertad, los grandes empresarios y las clases media alta y alta, sobre todo limeñas.

\subsection{Entre Sendero y la hiperinflación. Un desconocido quiebra el sueño de} los señores

En octubre de 1989 la polarización electoral era muy diferente a la de abriljunio de 1990. Izquierda Unida, dividida entre el sector que lideraba Henry Pease y el que dirigía Alfonso Barrantes Lingán, hacía sus últimos esfuerzos 
por recolocarse de cara al electorado de centro y centroizquierda que se oponía al Gobierno aprista, ya en debacle, y que temía el triunfo del FREDEMO.

El 28 de octubre de 1989, en respuesta al "paro armado" anunciado por Sendero Luminoso, cuya presión era intensa en Lima y en varias otras regiones del país, los integrantes de la plancha presidencial de la Izquierda Unida - Henry Pease, Agustín Haya y Gustavo Mohme - convocaron a una marcha para el 3 de noviembre, en aras de la paz y en clara demostración de rechazo al senderismo.

El candidato del FREDEMO expresó su disposición a participar en esa marcha. Así, la convocatoria contó con el aval de fuerzas políticas disímiles e importantes del escenario electoral, lo que le imprimió un fuerte carácter simbólico: ante la presión de Sendero Luminoso y el temor a una crisis generalizada del Estado y de la autoridad, la derecha, el centro político y la izquierda marcharon por las calles de Lima. Participaron la Izquierda Unida (Pease), FREDEMO, Acuerdo Socialista (Barrantes), la Democracia Cristiana y Acción Popular. La Iglesia católica, a través de la Conferencia Episcopal Peruana, también apoyó la marcha. El APRA, partido oficialista, rechazó intervenir en la "jornada cívica” de oposición a la violencia armada.

Esta marcha unitaria fue una de las más claras demostraciones de que la seguridad y el orden conformaban el eje del debate y la preocupación de la ciudadanía en general, y era un interés principal de la élite política.

Izquierda Unida, haciendo un esfuerzo por distinguirse del FREDEMO y su candidato Vargas Llosa, durante la referida marcha tuvo como lema principal “¡No matarás, ni con hambre ni con balas!”. Con la alusión al hambre, la izquierda intentaba distinguirse de la derecha; pero la unidad contra Sendero Luminoso expresaba la polarización principal que vivía la sociedad peruana. La marcha del 3 de noviembre se cerró a las dos de la tarde con un simbólico abrazo entre Henry Pease y Mario Vargas Llosa, al pie del monumento al almirante Miguel Grau, en el centro de Lima.

\subsection{Resultados electorales de la primera vuelta: Fujimori sustituye a la} Izquierda Unida ${ }^{9}$

El histórico apoyo ciudadano que obtuvieron el APRA y la Izquierda Unida en las presidenciales de 1985 se diluyó en cinco años. La razón: el Gobierno

9 Los resultados completos de las elecciones 1985 y 1990 se encuentran disponibles en https://bit. ly/2CcMdRA. 
aprista, con una pésima gestión económica, política y social del país; errores flagrantes de la clase política para enfrentar la guerra contra Sendero y el MRTA; la crisis interna de la Izquierda Unida; y la desconfianza ciudadana en los partidos tradicionales.

Si el APRA y la Izquierda Unida reunieron poco más de 5 millones de votos en 1985 ( $78 \%$ de votos válidos sobre un total de 6.5 millones de votos), en 1990 sumaron el 35\% (poco más de 2 millones de votantes), menos de la mitad de lo obtenido un lustro antes. El APRA obtuvo cerca de 22\%, cifra que reflejó el trabajo de una militancia que mantuvo su apoyo pese al Gobierno de García. En cinco años se deshizo su imagen de político joven y líder carismático, y se evaporó la probable solidaridad de ciudadanos que apoyaron con su voto a un partido históricamente vetado y perseguido (tablas 1 y 2).

La Izquierda Unida se dividió en 1989, a consecuencia de sus pugnas internas originadas por el sectarismo y los desacuerdos de estrategia política referidos a cómo actuar en esa coyuntura de crisis. Esto mermó el protagonismo que había obtenido desde principios de la década de 1980. El candidato de Izquierda Unida, Henry Pease, obtuvo 8\%; mientras que Alfonso Barrantes, representante de la Izquierda Socialista, logró apenas el 5\%; ambos resultados lejos del $25 \%$ que se alcanzara en 1985 . El porcentaje de votos perdidos se desplazó hacia Cambio 90 y su candidato Alberto Fujimori, quien proyectaba la imagen del hijo de migrantes que se formó profesionalmente a base de esfuerzo (en el imaginario nacional es usual vincular a los descendientes de origen japonés con el progreso), con independencia política (no pactó con ningún partido) y solvencia académica (agrónomo, rector y presidente de la Asociación Nacional de Rectores).

Los resultados de la primera vuelta electoral (8 de abril de 1990) le dieron el triunfo a Vargas Llosa, pero la diferencia con Fujimori era reducida y no aseguraba su victoria final, pese a la maquinaria propagandística a su favor impulsada desde los medios de comunicación. Tras conocer los resultados, Vargas Llosa le propuso a Fujimori "actuar patrióticamente", lo que se traducía en que retirara su candidatura para evitar una "innecesaria" segunda vuelta. Con buen cálculo, el candidato de Cambio 90 declinó la invitación: sumando los votos del APRA, de la izquierda y de otros adversarios del FREDEMO, derrotaría fácilmente a Vargas Llosa. 


\section{Cuadro 1}

ELECCIONES PRESIDENCIALES DE 1985, RESULTADO NACIONAL

\begin{tabular}{llrr}
\hline Candidato & Lista & Absolutos & \% \\
\hline Alan García & APRA & 3.452111 & 53 \\
Alfonso Barrantes & Izquierda Unida & 1605139 & 25 \\
Luis Bedoya & CODE & 773313 & 12 \\
Javier Alva Orlandini & Acción Popular & 471150 & 7 \\
Róger Cáceres & Izquierda Nacionalista & 91968 & 1 \\
Francisco Morales Bermúdez & FDUN & 54889 & 1 \\
& & & \\
Votos válidos & & 6500550 & 86 \\
Votos nulos & & 551584 & 7 \\
Votos blancos & & 492597 & 7 \\
Votos emitidos & & 7554836 & 91 \\
Ausentismo & & 788597 & 9 \\
Total de inscritos & & 8333433 & 100 \\
\hline
\end{tabular}

Fuente: Tuesta (2001).

\section{Cuadro 2}

ELECCIONES PRESIDENCIALES DE 1990: PRIMERA VUELTA, RESULTADO NACIONAL

\begin{tabular}{llrr}
\hline Candidato & Lista & Absolutos & \% \\
\hline Mario Vargas Llosa & FREDEMO & 2163323 & 33 \\
Alberto Fujimori & Cambio 90 & 1932208 & 29 \\
Luis Alva Castro & APRA & 1494231 & 22 \\
Henry Pease & Izquierda Unida & 544889 & 8 \\
Alfonso Barrantes & Izquierda Unida & 315038 & 5 \\
Róger Cáceres & FRENATRACA & 86418 & 2 \\
Ezequiel Ataucusi & FREPAP & 73974 & 1 \\
& & & \\
Votos válidos & & 6641584 & 85 \\
Votos nulos & & 569537 & 7 \\
Votos blancos & & 625995 & 8 \\
Votos emitidos & & 7837116 & 78 \\
Ausentismo & & 2176109 & 22 \\
Total de inscritos & & 10013225 & 100 \\
\hline
\end{tabular}

Fuente: Tuesta (2001). 


\section{Entre la segunda vuelta y la organización del Gobierno del orden}

La segunda vuelta (10 de junio) no hizo sino confirmar la tendencia que se configuraba desde febrero: la propuesta de shock de Vargas Llosa se convirtió en eje del debate político y las alianzas electorales. El peligro de Sendero se trasladó momentáneamente a un segundo plano, lo mismo que la crisis económica que el país heredaba del Gobierno de García.

El apunte de Alfredo Barnechea (1995, p. 378) respecto a que los resultados electorales de 1990 indicaban una modificación en el sentido común de los peruanos sobre el manejo de la economía es relevante: “[...] la población no se volcó hacia los candidatos de la izquierda o el APRA, lo que constituye un síntoma de que ya se había producido un vuelco en la cultura económica de los peruanos. Se dirigió hacia un candidato exótico e impensado, cuya ambición parecía ser apenas ocupar un escaño en el Senado". ${ }^{10}$

El esfuerzo del FREDEMO por centrar la atención en la crisis económica que el APRA había causado con su política heterodoxa fracasó; no logró captar suficientemente el interés ni despertó la preocupación de la mayoría. La identificación de Varga Llosa con la derecha y con los "ricos" tuvo un efecto superior a la hiperinflación. Fracasó la estrategia de la derecha política, económica y eclesial, y ganó la alianza APRA-Fujimori.

No obstante, la sui generis situación política permitió al APRA señalar, luego de la primera vuelta, que se confirmaba como la primera fuerza política organizada del país y como el partido mayoritario en el Congreso. No le faltaba razón: el FREDEMO era un frente de derecha y Cambio 90 una organización salida de la nada. Después de cinco años de Gobierno, con resultados económicos desastrosos, el oficialismo pudo darse el lujo de hacer esa afirmación. Tal fue, sin embargo, como se demostraría posteriormente, una apreciación cortoplacista.

La arremetida política y mediática del APRA, convertido en el gran definidor electoral gracias a su votación de más del $20 \%$, confirmó que la elección estaba zanjada. Mientras tanto, Cambio 90 había desmantelado electoralmente a la izquierda al ganar en buen número de distritos y departamentos que durante diez años se habían inclinado por esta tendencia.

La simple suma de la votación de Cambio 90 (27\%), el voto aprista (22\%) y el cerca de $14 \%$ de las dos listas de izquierda le otorgaban a Fujimori una

10 Fujimori postulaba a la presidencia y, al mismo tiempo, figuraba como cabeza de lista para el Senado, en virtud de una opción electoral entonces vigente. 
clara futura victoria. Las semanas entre la primera y la segunda vuelta, último periodo de apogeo del reformismo radical en el país, proyectaron la sensación equivocada de que se podía derrotar a la derecha al impedir que llegara al poder un candidato tan renombrado como Vargas Llosa.

Incluso el movimiento armado MRTA reconoció en la figura de Fujimori, dos semanas después de la primera vuelta, la expresión del "rechazo del pueblo" a los políticos de derecha, y calificó al FREDEMO como "el enemigo natural". Llamó a que la Izquierda Unida se sumara a su actividad armada e incluso un sector del MRTA planteó conceder una tregua de dos años al eventual y futuro Gobierno de Fujimori para que desarrollara una política a favor de los más necesitados.

El debate electoral continuó cada vez más áspero y no faltaron amenazas veladas o explícitas de intervención militar si Fujimori ganaba. Así, el general (r) Luis Cisneros Vizquerra afirmó: "Los golpes de Estado no se han eliminado en la historia política del Perú [...] ante el caos alguien tiene que sacar la cara y los más llamados a sacar la cara son las Fuerzas Armadas. Ojalá no se presente esta situación". ${ }^{11}$

Los problemas de fondo, como los vinculados a las finanzas, que después enfrentaría el Gobierno de Fujimori, seguían manifestándose: las Naciones Unidas anunciaban que el Perú y otras nueve naciones habían perdido el derecho a voto en la Asamblea General por falta de pago de sus cuotas, a pesar de que en Lima el Banco de la Nación informaba que se había cancelado el monto adeudado, con lo cual se regularizaba la situación. El embajador de los Estados Unidos en el Perú señalaba que su Gobierno no tenía ningún propósito de enviar tropas norteamericanas para operaciones en el Alto Huallaga ni en otro lugar del Perú, pero añadía: "Lo que sí estamos dispuestos a hacer es enviar entrenadores policiales y militares, si lo quiere el Gobierno peruano".

En mayo de 1990 se inició una nueva ofensiva del APRA, a través de su excandidato presidencial Luis Alva Castro, quien anunció en un mensaje por el Día del Trabajador que la militancia de su partido saldría a las calles para defender la estabilidad laboral, garantizar la gratuidad de la enseñanza y, sobre todo, cerrar el paso a la ilusión de aplicar el shock que tenía la derecha, representada en el FREDEMO. La polarización política no podía ser más clara: se enfrentaban las fuerzas de la derecha, agrupadas en torno a un programa conservador neoliberal, contra las que representaban el sentido común insta-

11 Expreso, 29 de marzo de 1990. 
lado en el país desde la década de 1970, encarnados en variantes políticas que iban desde el reformismo moderado hasta el más radical.

La campaña organizada por el FREDEMO para desprestigiar a Fujimori fracasó. Las denuncias sobre supuestos delitos del candidato relacionados con la subvaluación - y la consiguiente evasión tributaria - en la compra-venta de casas y departamentos cayeron en saco roto. La gran mayoría de la población no se interesó por (o no creyó en) este tipo de argumentaciones o las minimizó ante la esperanza de una alternativa favorable.

\subsection{Segunda vuelta: la suerte echada}

Las encuestas de intención de voto para la segunda vuelta electoral daban a Fujimori aproximadamente 50\%. A un mes del proceso, una encuesta del grupo Lacey Bits Bytes señaló que el 77\% de quienes habían votado por Alva Castro (APRA) lo harían por el candidato de Cambio 90, además de alrededor del 60\% de los que habían marcado por Pease o Barrantes. En la gran Lima, según Datum, Vargas Llosa aún aventajaba a Fujimori por un estrecho margen: $46.3 \%$ frente a $41.7 \%$.

Induciendo la polarización política contra la propuesta neoliberal de Vargas Llosa, el APRA, aún en el Gobierno, restituyó, mediante la Ley N. ${ }^{\circ}$ 25210, el derecho de los trabajadores de hospitales y clínicas particulares a tener un solo procedimiento de negociación colectiva. Otra señal de la voluntad del entonces presidente García de confrontar con el programa de Vargas Llosa fue la Ley del Profesorado, Ley N. ${ }^{\circ}$ 25212, promulgada el 17 de mayo, que otorgó beneficios económicos y laborales al gremio magisterial.

En esas semanas las acciones de Sendero Luminoso continuaron en el campo y en algunas ciudades. Una de las más dramáticas fue el asesinato selectivo de dirigentes del APRA: a fines de abril, Felipe Santiago Salaverry (exdirector del Seguro Social); y el 14 de mayo, en Piura, el regidor José Manuel Garavito Barba.

La campaña de la Iglesia católica se mantuvo firme contra los grupos evangélicos que formaban parte de la alianza aglutinada alrededor del candidato Alberto Fujimori. El obispo de Lima, cardenal Augusto Vargas Alzamora, afirmó que los evangélicos no responden a la tradición cristiana. Dos días después, en respuesta a esta opinión, el secretario general del Concilio Nacional Evangélico del Perú, Pedro Merino Boyd, negó que las iglesias evangélicas propiciaran una campaña contra la Iglesia católica. Los últimos días de mayo 
se informó que la procesión del Señor de los Milagros saldría por las calles en acto de desagravio contra presuntas declaraciones de sectores evangélicos de Cambio 90. El candidato Fujimori respondió a la defensiva asegurando que su Gobierno no modificaría ningún punto del texto constitucional referido a las relaciones entre la Iglesia católica y el Estado peruano.

La tensión se agudizaba y eran claros los dos grandes bloques: el del FREDEMO, liderado por Vargas Llosa, que proponía una reforma radical de derecha del Estado y de la economía, y el dirigido por el APRA, con Cambio 90, que se anunciaba partidario del papel decisivo del Estado en la economía y en la política, intentando bloquear, a pesar de la crisis, la propuesta de la derecha neoliberal.

La improvisación de la candidatura de Fujimori resultó evidente: ante las críticas de sus adversarios respecto a su falta de programa, se vio obligado a publicar una improvisada versión en el diario Página Libre, afín a su candidatura: "Plan de Gobierno de Cambio 90: una propuesta para el Perú". ${ }^{12}$

En este lapso, entre la primera y la segunda vuelta, comenzó a quedar claro que la izquierda perdía toda iniciativa política. La dimensión de su derrota era evidente. Los primeros días de junio, el Partido Socialista Revolucionario (PSR) fue uno de los primeros en declarar su acuerdo de votar por el candidato de Cambio 90. En paralelo, había indecisión en las filas de las dos mayores agrupaciones de izquierda: Izquierda Unida y Acuerdo Socialista.

Será recién después del debate presidencial entre Vargas Llosa y Fujimori cuando la Asamblea Nacional Popular, a través de su presidente, el diputado electo de Izquierda Unida Ricardo Letts, llamaría a respaldar a Fujimori. Una decisión semejante dieron a conocer en un comunicado la Central General de Trabajadores del Perú (CGTP), el Movimiento Manuela Ramos, la Federación Nacional de Trabajadores Marítimos y Portuarios del Perú, el Sindicato de la Compañía Peruana de Teléfonos y las comunidades nativas ashánincas. El gremio de choferes de Lima y Callao respaldó en solitario la candidatura de Vargas Llosa.

El APRA se manejó abiertamente, desde el poder, a favor de la candidatura de Fujimori. Desde Trujillo, a fines de mayo, dio a conocer una nueva declaración pública en la que ratificaba que su militancia no votaría por la derecha y rechazaría el proyecto neoliberal. El presidente García declaró que deploraba la "campaña sucia" que estaba desplegando la derecha contra el candidato Alberto Fujimori. Una muestra más del empeño aprista por ganar

12 Página Libre, 21 de abril de 1990. 
puntos en las encuestas y votos en las urnas a favor de Fujimori fue la promulgación de otras dos leyes de carácter laboral: negociación colectiva por rama de actividad económica y compensación por tiempo de servicio.

El 4 de junio tuvo lugar el debate televisivo entre los dos candidatos, última gran esperanza del FREDEMO: el escritor Mario Vargas Llosa, reconocido mundialmente, podía y debía barrer al desconocido ingeniero Alberto Fujimori. Sin embargo, el resultado fue una desilusión para los partidarios del FREDEMO. Incluso el candidato de Cambio 90 dio un golpe mediático al presentar una edición del diario Ojo que daba como ganador del debate a Vargas Llosa antes de que se hubiera realizado, con lo que denunció lo que señalaron como manipulación informativa de un sector del periodismo.

\subsection{Segunda vuelta: frente a un ganador}

La segunda vuelta electoral se realizó el domingo 10 de junio y esa misma noche se confirmó el triunfo de Fujimori (tabla 3). El presidente García afirmó que la concertación y la concordia se imponían como principales tareas a ser encaradas por el nuevo Gobierno. Así, insinuaba su afán de monitorear el futuro Gobierno, y sentaba pautas antes de su instalación formal. El aprismo se esforzó por anclar al nuevo Gobierno en un espacio político en el que pudiera seguir teniendo una influencia decisiva, más aún cuando gracias a su importante representación parlamentaria su influencia en el Congreso era incuestionable.

\section{Tabla 3}

ELECCIONES PRESIDENCIALES 1990: SEGUNDA VUELTA, RESULTADO NACIONAL

\begin{tabular}{llll}
\hline Candidato & Lista & Absolutos & \% \\
\hline Alberto Fujimori & Cambio 90 & 4489897 & 62 \\
Mario Vargas Llosa & FREDEMO & 2708291 & 38 \\
Votos válidos & & 90 \\
Votos nulos & 7198188 & 8 \\
Votos blancos & 604598 & 2 \\
Votos emitidos & 155446 & 80 \\
Ausentismo & & 20 \\
Total de inscritos & 7958232 & 100 \\
\hline
\end{tabular}

Fuente: Tuesta (2001). 
El 11 de junio, El Comercio, que había sostenido la candidatura de Vargas Llosa, advertía: "Alberto Fujimori resulta ser el nuevo jefe de Estado, [pero] se sigue desconociendo todavía qué propuesta llevará a Palacio para inaugurar su Gobierno en el periodo 90-95". ${ }^{13}$ Ese mismo día, alrededor de trescientas personas de clase media alta y alta, la mayoría vestidas de riguroso luto, desfilaron por calles de Miraflores, hacia la casa de Vargas Llosa.

Eran las reacciones opuestas ante el triunfo del candidato de Cambio 90: el APRA lo consideraba un triunfo suyo y trataba de trazar pautas para el nuevo Gobierno; la derecha mostraba su desazón por la derrota de un candidato "de lujo" para el Perú. Los fredemistas salieron una vez más a la calle en caravanas, el 12 de junio, dos días después de la derrota de su candidato, a los gritos de: "Y va a caer, y va a caer, el chino'e mierda va a caer"; una actitud provocadora, racista y golpista.

En el ámbito internacional, el Gobierno japonés se movilizó a favor del presidente electo. Una delegación de representantes de empresas japonesas con sede en el Perú visitó a Fujimori. Se le sumaron funcionarios de la embajada y de la empresa Jetro, organismo estatal japonés dedicado a promover el intercambio comercial.

\section{Entre la segunda vuelta y el 28 de julio de 1990: los primeros ajustes del proyecto individual del presidente electo}

Las ilusiones de los que apoyaron a Fujimori desde el APRA, la izquierda y el amplio abanico reformista se comenzarían a desvanecer con prontitud. A menos de una semana de su triunfo, y como parte de su afán de hegemonizar en su propia agrupación, Fujimori impuso a dedo como secretario general de Cambio 90 a Andrés Reggiardo. Esto originó una intensa protesta entre bases de su agrupación política en Lima y ocho ciudades del interior del país, que reconocían a Víctor Homma como su secretario general. ${ }^{14}$

13 El Comercio, 11 de junio de 1990.

14 Cambio 90 aglutinaba a integrantes de, por lo menos, tres ramas: los de la Universidad Agraria, personalmente cercanos a Fujimori; los cercanos a Máximo San Román, primer vicepresidente y representante de los pequeños industriales; y los allegados a Carlos García y García, segundo vicepresidente, relacionado con grupos religiosos evangélicos. Reggiardo era ingeniero zootecnista de la Universidad Agraria, de donde venía su nexo con Fujimori. 


\subsection{Adiós a los partidos (y a los aliados electorales)}

A una semana de su elección, Fujimori descartó la posibilidad de establecer pactos políticos con los partidos que lo apoyaron. Solo mencionó de manera gaseosa la necesidad de llegar a un consenso con partidos y organizaciones sindicales. ${ }^{15}$

En este contexto, el primer vicepresidente, Máximo San Román, se aventuró a formular un llamado - en la actualidad impensable - a los integrantes del MRTA y de Sendero Luminoso para que depusieran las armas e intervinieran en la "reconstrucción nacional". Un día después, el cardenal Augusto Vargas Alzamora, recogiendo la preocupación del vicepresidente, declaró: "El Perú necesita una tregua definitiva de los terroristas, porque las ideas no se imponen con las armas, sino con las razones". ${ }^{16}$ Con Sendero Luminoso y el MRTA activos, y después de un proceso electoral particularmente tenso, diversos sectores de la opinión pública no descartaban la conveniencia de algún tipo de diálogo político con los movimientos subversivos. Esta opinión fue compartida por parlamentarios que propusieron a la Iglesia católica como interlocutora en ese probable diálogo.

El 21 de junio, diez días después de la elección de Fujimori, el segundo vicepresidente electo, Carlos García García, consideró muy positivo un anuncio de tregua formulado por el líder del MRTA, Víctor Polay. Sin embargo, la revista Cambio, cercana a las posiciones políticas de esta organización, desmintió la propuesta de tregua.

El presidente García, con el ánimo de congraciarse con el presidente electo, observó la ley que nivelaba los salarios de los empleados y profesionales del Ministerio de Salud con los del Instituto Peruano de Seguridad Social.

Uno de los primeros que reparó en que los esfuerzos del APRA por copar al nuevo mandatario podían fracasar fue Manuel D'Ornellas, director del diario Expreso: "El presidente electo ha querido demostrar que no suscribe la política ante el FMI ${ }^{17}$ de García" y "ha sostenido que él está más cerca de Mario Vargas Llosa que de Alan García Pérez [...]. Por impedir la victoria de

15 Julio Cotler (1993, p. 22) afirma, con relación a este periodo y a los meses venideros: “[...] el flamante presidente, con la habilidad propia de un tradicional y experimentado político, fue creando lazos de apoyo y neutralizando oposiciones sin comprometerse en alianzas que pudieran limitarlo; mientras tanto apelaba al 'pueblo' contra la ineficiencia y corrupción política, que convirtió en temas de su repertorio y que le otorgarían valiosos dividendos".

16 Recogido en varios diarios, 18 de junio de 1990.

17 Fondo Monetario Internacional. 
Mario Vargas Llosa, el Gobierno respaldó impúdicamente a Alberto Fujimori. Pero ahora Fujimori quiere, por lo visto, emanciparse de esa tutela". ${ }^{18}$

Una declaración del 22 de junio constituyó una señal de lo que sería el nexo más consistente de Fujimori durante su Gobierno: aseguró que sus relaciones con las Fuerzas Armadas eran y serían excelentes, y que ello se traduciría en acciones de colaboración y participación tanto en el combate a la subversión armada como en obras vinculadas al desarrollo nacional.

\subsection{El fin de un romance fortuito y el inicio de nuevos amores}

El inicial esfuerzo de Fujimori por desmarcarse del APRA y de quienes lo habían apoyado durante la segunda vuelta se reiteró: la ONU, con el embajador peruano Javier Pérez de Cuellar como secretario general, ofreció sus buenos oficios para que el presidente electo se reuniera con el Fondo Monetario Internacional. Simultáneamente, personas cercanas al equipo económico de Fujimori — formado apresuradamente entre la primera y la segunda vueltacomenzaron a renunciar; el primero fue el economista Óscar Ugarteche, proveniente de la izquierda. El 27 de junio, a pocas horas de viajar Fujimori a los Estados Unidos, se conoció que había graves desacuerdos frente al programa económico que se debía presentar a las entidades crediticias internacionales con las que se negociaría.

El equipo económico original de Fujimori fue desmontado con la misma premura con la que fue constituido. El presidente electo había tomado contacto con Hernando de Soto, presidente del Instituto Libertad y Democracia (ILD) ${ }^{19}$ con excelentes relaciones en las Naciones Unidas y el mundo financiero internacional. ${ }^{20}$ El expresidente del directorio del Banco de la Nación y

18 Expreso, 19 de junio de 1990.

19 Cotler (1993, p. 20) traza un perfil político de Hernando de Soto: "Desde mediados de los ochenta, Hernando de Soto (1984) inició una eficaz crítica liberal del orden patrimonial que cobró inusitada vigencia a partir de la debacle producida por García. Ella se funda en que la irresponsabilidad política de los gobernantes, 'dictadores electos por cinco años', permitía al Estado, vía los partidos, otorgar prebendas de tipo 'mercantilistas' que frenaban el desarrollo de las iniciativas individuales, especialmente de los más pobres, bloqueando el desarrollo del mercado y fomentando la corrupción".

20 "Al iniciar su Gobierno, Fujimori se encontró con la necesidad urgente de estabilizar la economía y derrotar a la subversión. Como también lograr estas metas mediante el fragmentado poder político en el Congreso y las reglas de juego constitucionales desarrolladas a partir de 1980 [...]. La primera decisión clave adoptada por Fujimori fue la de gobernar con el apoyo de la comunidad financiera internacional y adoptar un plan de estabilización económica ortodoxa —un programa de shock-, abandonando sus promesas electorales. Diez días después de emerger victorioso en la segunda vuelta electoral contra Vargas Llosa, Fujimori ya estaba dejando atrás la imagen del candidato populista 
futuro canciller, Augusto Blacker Miller, adelantó el camino que debía transitarse: "Comencemos a pagar los pecados de los excesos cometidos en los últimos cinco años. Creo que esto es algo importante, que hay que entenderlo para no volverlo a cometer. La economía artificial de crecimiento comenzó a sentar la base de la distorsión que ahora pagamos". ${ }^{21}$

En un esfuerzo por sostener y darle continuidad a políticas de su Gobierno, el todavía presidente Alan García sostuvo que la rebaja sustancial de la deuda pública de América Latina con los Estados Unidos, anunciada por el presidente norteamericano George Bush, demostraba que la posición peruana asumida por su Gobierno desde hacía cinco años sí tenía sentido. "Andamos en el camino de la historia", afirmó.

El quiebre de la efímera alianza reformista constituida para derrotar a Vargas Llosa sería una ruptura sin retorno. Se iniciaría un cambio sustantivo de la economía peruana y del papel que había cumplido el Estado durante los últimos veinte años. Liderada por Fujimori, comenzaban a sentarse las bases de una sólida alianza política con las Fuerzas Armadas, con poderes fácticos nacionales y con centros de poder internacionales, sobre todo multilaterales y transnacionales, en ese momento sostenidas por el FMI.

El 1 de julio, el exministro de Economía del Gobierno aprista, Abel Salinas, negociador de la deuda externa durante los meses finales del Gobierno de su partido, expresó su preocupación frente a los avances de Fujimori en la reunión con los máximos representantes del FMI, el Banco Mundial y el Banco Interamericano de Desarrollo.

En la otra acera, comenzaban a cambiar de semblante los que habían lamentado la derrota de Vargas Llosa pocas semanas antes. Así, Expreso señalaba: "Alberto Fujimori sigue sorprendiendo gratamente; no cabe duda de que su viaje ha sido positivo: ha dejado dos cosas, un verdadero apoyo del director del Fondo Monetario Internacional, y la conformación de un grupo de trabajo encargado de asesorar la preparación de un programa económico". ${ }^{22}$

En la misma dirección declaraba De Soto, al confirmar la decisión de Fujimori de privatizar las empresas públicas que no fueran las principales ni las estratégicas. Constituido en práctico vocero transitorio del presidente electo, adelantó la posibilidad de un referéndum para saber si el pueblo aceptaba o

y heterodoxo para asumir el rol de un presidente electo ortodoxo y ajustador" (Resumen Semanal de Desco, 22-27 de junio de 1990).

21 Varios diarios, 27 de junio de 1990.

22 Expreso, 3 de julio de 1990. 
no un pacto con los organismos internacionales de crédito. La razón esgrimida: la situación económica del país seguía siendo desesperada.

El 8 de julio los medios de comunicación informaban, luego del retorno de Alberto Fujimori de su gira por los Estados Unidos y Japón, que el presidente electo planteaba la necesidad de un reajuste económico drástico, concreto y pragmático, que incluía un impuesto básico por una sola vez sobre los ingresos de quienes más ganaban.

El 9 de julio se produjo la fuga de cuarenta y ocho miembros del MRTA del penal Miguel Castro Castro a través de un túnel construido por los reclusos. Los críticos del APRA insinuaron complicidad del presidente García, debido a su antigua amistad con Víctor Polay, jefe principal del MRTA, detenido en esa prisión y con una previa militancia aprista.

La crisis del equipo económico de Cambio 90 fue definitiva el 16 de julio con la renuncia del economista Santiago Roca, quien había oficiado como jefe del programa de Gobierno de Cambio 90. El 17 de ese mismo mes, las fuerzas reformistas de izquierda, ya alertadas frente al acelerado e inconsulto cambio de posición de Fujimori, indujeron a la Confederación Campesina del Perú (CCP), agrupación gremial liderada por el Partido Unificado Mariateguista (PUM), a llamar a las organizaciones políticas y populares a una movilización para exigir el cumplimiento de las promesas de campaña. La alianza ganadora ya estaba rota antes de la asunción del mando del nuevo presidente.

El 18 de julio, en una muestra de que las decisiones se adoptarían con celeridad y sin consideración para con sus efímeros aliados, Fujimori presentó como futuro ministro de Economía y Finanzas a Juan Carlos Hurtado Miller, ministro de Agricultura del segundo Gobierno de Fernando Belaunde. Este anuncio se produjo después de una reunión de tres horas sostenida entre ambos en el Círculo Militar, ambiente físico desde el cual Fujimori despachó regularmente durante las semanas previas y posteriores al 28 de julio.

\section{Se prepara el ambiente para el shock: con partidos, no; con personalidades, sí}

El presidente electo invitó a integrantes de Izquierda Unida a formar parte su primer gabinete ministerial. El juego político de Fujimori y de su entorno dio señales de habilidad y oficio: se alejó del APRA, fuerza amenazante dada su votación y su alto número de parlamentarios; rompió sus "compromisos" 
electorales y pactó con nuevos aliados en el exterior (sobre todo con el FMI), pero paralelamente le tendió una mano a la Izquierda Unida para neutralizarla y dividir a las fuerzas que la habían apoyado durante la segunda vuelta —APRA, Izquierda Unida y Acuerdo Socialista—. Nombró como ministros a dos militantes de izquierda: al diputado Fernando Sánchez Albavera en la cartera de Energía y Minas, y a Gloria Helfer en Educación.

Alan García, en un esfuerzo por impedir lo que comenzaba a ser una amenaza a su proyecto de mantener su influjo político y al Perú fuera de la influencia del FMI y sus programas, declaró que las centrales sindicales estaban llamadas a luchar contra el shock económico que se preparaba. El futuro ministro de Economía, Juan Carlos Hurtado Miller, confirmó el anunció esperado seis días antes del 28 de julio al declarar que, efectivamente, se aplicaría un programa de ajuste para cerrar tres brechas: la fiscal, la deuda exterior y la pobreza.

El 26 de julio, como para indicar que la posibilidad de diálogo con el Gobierno electo se había cerrado, un cohete Instalazza probablemente lanzado por el MRTA impactó en los faroles de fierro forjado de Palacio de Gobierno. A la misma hora, otro comando incendió un ómnibus que transitaba por una avenida principal del populoso distrito de Villa El Salvador; y, más tarde, tres subversivos ingresaron a la agencia de noticias alemana DPA para transmitir un mensaje al exterior.

El país, extenuado, esperaba el fin del Gobierno aprista y se preparaba, con una buena dosis de incertidumbre y resignación, a recibir al nuevo mandatario: "Felizmente, mañana es la transmisión del mando de Alan García a Alberto Fujimori. Durante cinco años, nos ha gobernado la ineptitud y la improvisación, cubiertas ambos por un manto de arrogancia”, escribía D’Ornellas. ${ }^{23}$

El golpe militar preparado por un sector conservador de las Fuerzas Armadas quedó en suspenso ante los cambios del presidente electo: "El pronunciamiento militar previsto para el 27 de julio por la última apreciación de inteligencia anexa al Plan Político-Militar se volvía improcedente en el momento en que Fujimori accedía a realizar las metas de dicho plan. [...] Esta versión perfeccionada y, al mismo tiempo, mediatizada del Plan PolíticoMilitar fue puesta en vigor por Montesinos y Fujimori en las conspiraciones de junio. Así quedaron fuera de lugar las fantásticas instituciones secretas de que hablaba el Plan [... y también la Junta de Gobierno. Pero el Gobierno en

23 Expreso, 27 de julio de 1990. 
la sombra sí existiría. Su sede sería el SIN y todas sus funciones serían dirigidas por Vladimiro Montesinos" (Reátegui, 2009, p. 164).

\subsection{La juramentación y los primeros desenlaces}

Luego de recibir la banda presidencial de su antecesor, Alberto Fujimori, en su discurso del 28 de julio de 1990, definió como línea central de su Gobierno justificar el inicio de un nuevo periodo político sobre la base de proponerse superar el caos político y el desastre económico. Prometió luchar contra la corrupción y el narcotráfico, que había logrado "penetrar también la esfera del Estado" (Fujimori, 1990, p. 1), asimismo, aseguró que su Gobierno respetaría escrupulosamente la libertad de información y crearía condiciones necesarias para un mejor ordenamiento del mercado, "la distribución equitativa de la riqueza [...] [y] una verdadera economía social de mercado" (Fujimori, 1990, p. 3), que no pretende privatizar todas las empresas públicas. ${ }^{24}$

Respecto a la guerra interna, sostuvo que "solo la eliminación definitiva de la injusticia y la marginación puede acabar con la subversión armada". Afirmó que su Gobierno le daría "efectiva prioridad al desarrollo de las zonas andinas y de la selva de nuestro país, hoy convulsionadas por el terrorismo" (Fujimori, 1990, p. 9), dejando abierta la posibilidad de entablar un diálogo "con los grupos alzados en armas, siempre que estos las depongan; el pueblo me ha elegido, entre otras cosas, para buscar la unidad de los peruanos, incluidos los equivocados" (Fujimori, 1990, p. 9). Se comprometió a respetar y promover los derechos humanos, y sostuvo que sería una firme línea de acción de su Gobierno. Culminó su mensaje con una interpretación de los resultados electorales y las expectativas ciudadanas: "El 10 de junio tu voto fue por la esperanza. Este país que perdía el rumbo, esta sociedad, cansada de la demencia de la demagogia y la inoperancia gubernativas, acudió al llamado de un mensaje de renovación. Apostó nuevamente por democracia y nos toca a los hombres hoy en el Gobierno ser fieles a su mandato" (Fujimori, 1990, p. 11).

Comienza así un capítulo decisivo en la historia política del país del fin del siglo XX y comienzos del XXI: para que el país fuera viable debía producirse un viraje decisivo de la política económica, y el Estado debía ser capaz de garantizar un orden básico. Estaba en disputa, sin embargo, el camino para alcanzar tales objetivos: la opción por la que había votado el país en la segun-

24 Finalmente, el primer Gobierno fujimorista cede a las exigencias del FMI y se alínea con el Consenso de Washington. 
da vuelta; el proyecto de Vargas Llosa, de un Perú neoliberal y democrático representativo; la alternativa de Sendero Luminoso, de un cambio radical sustentado en una propuesta totalitaria; y un neoliberalismo de corte dictatorial.

El proceso de optar sería tortuoso y se perfilaría con el pasar de los acontecimientos. Las otras alternativas - socialdemocracia aprista, izquierda reformista radical electoral y derecha socialcristiana - quedarían en breve fuera de carrera. El hecho anecdótico y paradojal era que el país era testigo del tránsito de un régimen constitucional a otro por tercera vez consecutiva, y esto por primera vez en el siglo XX.

Julio de 1990 concluyó con los altos mandos de las Fuerzas Armadas intentando poner fin a los rumores de golpe militar que habían surgido como producto de la derrota de Mario Vargas Llosa. ${ }^{25}$ Hablando en nombre de las Fuerzas Armadas, el ministro de Defensa, general Jorge Torres Aciego, testimonió la lealtad de las "instituciones tutelares del Perú" a su jefe supremo, el presidente Alberto Fujimori. Tales declaraciones no podían esconder que ciertos militares en actividad y algunos retirados habían elaborado el Plan Verde, un remedo del proyecto de Augusto Pinochet aplicado en Chile, y que había inquietud en los cuarteles sobre la gestión del presidente electo. El cambio inmediato de una serie de altos mandos militares después de la asunción de Fujimori evidenció la necesidad de "poner orden" en las Fuerzas Armadas, para lo cual era preciso desplazar a los oficiales que le generaban desconfianza.

\section{A modo de cierre}

Dos aspectos centrales sobrepasan la repercusión coyuntural de ese breve periodo: i) el cambio radical del modelo económico en pro de uno neoliberal y la consecuente fundación de la legitimidad del Estado y del régimen político en la supremacía de la economía; y ii) la consolidación, desde el Gobierno, de un discurso político antiinstitucional y antipartidario, y la (consecuente) reconstrucción política autoritaria del poder político central.

Particularizan a este lapso cuatro hechos de carácter más coyuntural, pero no por ello menos decisivos: i) el renovado incremento de la violación de

25 "El primer acto de Fujimori como presidente fue clarísimo al respecto: el mismo día que juramentó, mandó al retiro a los comandantes generales de la Marina de Guerra y de la Fuerza Aérea" (Kenney, 1997, p. 86). 
los derechos humanos; ii) la captura, por la Policía Nacional, de Abimael Guzmán; iii) la construcción de una amplia alianza de poderes fácticos; y iv) el apoyo mayoritario de la opinión pública al autogolpe de Estado. En síntesis: la coyuntura definió un escenario de cambios acelerados con efectos de larga duración. 


\section{Bibliografía}

Arendt, H. (1997). ¿Qué es la política? Barcelona: Paidós.

Barnechea, A. (1995). La república embrujada. Lima: Santillana.

Cotler, J. (1993). Descomposición política y autoritarismo en el Perú. Documento de trabajo, 51. Serie Sociología y Política, 7. Lima: IEP.

Comisión de la Verdad y la Reconciliación (2004). Informe final. Lima: CVR.

Eguiguren, F. (1986). Defensa nacional, estados de excepción y control del orden interno en la Constitución peruana de 1979. Defensa Nacional, 6, pp. 25-37.

Fujimori, A. (1990). Mensaje a la nación, 28 de julio de 1990. Lima: Congreso de la República. Recuperado de: https://bit.ly/2PD7Tu4.

Kenney, C. (1997). ¿Por qué el autogolpe? Fujimori y el Congreso 1990-1992. En F. Tuesta (Ed.). Los enigmas del poder: Fujimori 1990-1996. Lima: Fundación Friedrich Ebert.

Lenin, V. I. (1915). La bancarrota de la II Internacional. Recuperado de: https://bit.ly/2ISCEs6.

Lynch, N. (1999). Una tragedia sin héroes. La derrota de los partidos y el origen de los independientes. Perú 1980-1992. Lima: Fondo Editorial de la Universidad Nacional Mayor de San Marcos.

Reátegui, F. (2009). El sistema político durante el proceso de violencia. Selección de textos del Informe final de la CVR. Lima: IDEHPUCP.

Schmitt, C. (2007). La dictadura. Madrid: Alianza Editorial.

Tuesta, F. (2001). Perú político en cifras. 1821-2001. Lima: Fundación Friedrich Ebert.

Weber, M. (2004). La politica como profesión. Madrid: Espasa Calpe. 